\title{
PELATIHAN SENI DEKORASI DI SEMINARI MENENGAH AGUSTINIANUM TOMOHON
}

\author{
Budiyatmi \\ Fakultas Bahasa dan Seni, Universitas Negeri Manado \\ email: budiyatmi53@gmail.com
}

\begin{abstract}
Competition in all sectors and of human life: in local, national and global, requires the role of art education as a strategic choice. Arts education as part of character education is to obtain aesthetic experience and discover the value of beauty. Tomohon as one of the tourist city has a natural potential and veryinteresting to visit. Predicate 'city offlowers' is an attraction in itself too. Business opportunities in the field of Flora, make businessmen and investors keep to develop business in the field of this industrial. Then training dercoration art or art flower arrangement, became a media that needs to be selected in the creation of quality works. Media is easily obtained and if they supported with a design concept, this is can be interesting artwork in the middle of the competition and the development of applied arts. The charm of the plant is able to present the beauty of the room decor. They can complete by combining various types offlowers in a container, and inserted along with a variety of foliage. Set of parts of the plant will appear more attractive if they knew about the art of stringing. The problem is, there have some basic things who can make wild flowers or leaves to make it look attractive. Based on these ideas, skills need to be provided in an attempt to tackle the problem a lack of interest to pursue business in the field of art is one of the alternatives to bring in additional revenue source.
\end{abstract}

Keywords: art education, aesthetic values, flora, flower, decoration. 


\section{PENDAHULUAN}

Dalam suasana persaingan yang ketat pada semua sektor dan lingkup kehidupan manusia, baik secara lokal, nasional maupun global, peran pendidikan seni menjadi pilihan yang strategis. Ketrampilan dibidang seni merupakan media yang diharapkan mampu memberikan jawaban terhadap tuntutan jaman. Pendidikan seni sebagai bagian dari pendidikan karakter bertujuan agar seorang dapat memperoleh pengalaman estetik dan menemukan nilai-nila i keindahan. Melalui pendidikan seni dapat mengembangkan minat kesukaan anak, menghargai keindahan dalam kehidupan. Pada kemudian hari dapat mengembangkan panggilannya menyalurkan kesukaannya berekspresi dan berkreasi.

Tomohon sebagai salah satu kota tujuan wisata memiliki potensi alam yang sangat menarik untuk dikunjungi turis. Predikat sebagai kota bunga juga merupakan daya tarik tersendiri yang mengundang turis Mancanegara maupun Domestik untuk datang berkunjung. Maka peluang usaha dibidang Flora ini membuat pengusaha/ investor tergiur untuk mengembangkan berbagai bisnis dibidang industri bunga. Keberadaan bisnis bunga potong sangat marak di kota ini. Nampak di desa Kakaskasen berjajar kios-kios penjual bunga potong atau bunga segar. Sepertinya menjadi budaya bahwa setiap hari minggu, Gereja dihiasi dengan aneka bunga segar sebagai hiasan dekorasi Altar. Berbagai hajatan atau pesta misalnya pernikahan, pesta Ulang Tahun dsb, dipenuhi dengan dekorasi bunga segar.

Bunga bukan merupakan sesuatu yang baru untuk bangsa Indonesia, karena berbagai jenis bunga sudah ada di seluruh daerah di Indonesia. Sejak dahulu, setiap daerah di Indonesia sudah menggunakan bunga untuk berbagai macam upacara adat, seperti dalam upacara kelahiran, perkawinan, atau kematian. Bunga yang digunakan di dalam upacara adat tersebut ditata atau dirangkai sedemikian rupa dengan penuh cita rasa dan sentuhan seni. Pada saat ini kecintaan masyarakat

Indonesia akan bunga makin meningkat. Halitu memotivasi para pencinta bunga untuk melakukan berbagai kegiatan, seperti kegiatan pameran flora, perlombaan merangkai bunga, seminar, workshop atau pelatihan, dan sebagainya. Kegiatan-kegiatan tersebut membuka mata masyarakat lebih luas sekaligus mengubah selera konsumen akan bunga, sehingga masyarakat Indonesia berlomba untuk menampilkan rangkaian bunga terbaik dan terindah.

Pada saat ini industri bunga di Indonesia berkembang sangat pesat. Hal itu ditandai dengan banyaknya usaha industri bunga yang melayani kebutuhan masyarakat, seperti dekorasi rumah, gedung, serta munculnya lembaga-lembaga pelatihan atau kursus merangkai bunga.

Berbicara tentang seni merangkai bunga dan desain floral, kita dituntut untuk memahami materi floral sebagai sarana atau obyek yang akan dibentuk menjadi suatu karya seni. Untuk itu kita perlu mempelajari pengetahuan tentang sifat dan karakter materi floral sehingga kita dapat memilih materi floral yang tepat sesuai dengan rangkaian yang akan dibuat.

Merangkai bunga merupakan sebuah seni yang dapat dipelajari oleh setiap orang. Dari penguasaan dasar merangkai bunga diharapkan seseorang termotivasi untuk menciptakan suatu rangkaian bunga yang indah sesuai dengan daya kreativitasnya.

Mengingat akan hal ini, dan memposisikan strategi untuk mempersiapkan tenaga-tenaga trampil dan berpengalaman dalam bidang seni rupa maka sangat diharapkan kerjasama antar tenaga akademisi dan lembaga-lembaga strategis untuk membangun satu kekuatan dalam mendidik putra putri bangsa dari lingkup pendidikan dasar, menengah sampai perguruan tinggi. Peserta yang dipersiapkan untuk mengikuti pelatihan Desain Floral atau Seni Merangkai Bunga ini adalah siswa-siswa di Seminari Agustinianum Tomohon.

\section{RUMUSAN MASALAH}

Sebagai lembaga pendidikan lanjutan yang bertujuan mengembangkan minat dan bakat peserta didik maka kegiatan ini sangat penting untuk dilaksanakan dengan harapan dapat memberi manfaat yang berartibagi peserta yang dilatih termasuk guru-guru yang terundang maupun dengan sukarela beraktivitas bersamasama dengan peserta didik. Kegiatan ini menjadi pendorong semangat bagi peserta didik yang ingin berkreasi dalam bidang seni rupa. Karena bidang seni rupa melahirkan tenagatenaga cakap , trampil, kreatif dan profesional di bidangnya. 
Berdasar pada pemikiran tersebut, penulis sebagai pendidik dibidang seni yaitu seni rupa, merasa terpanggil untuk memberikan bekal ketrampilan dan berpartisipasi aktif dalam menanggulangi permasalahan yaitu : Kurangnya Sumber Daya Manusia di bidang Seni rupa, khususnya bidang seni dekorasi karena kurangnya minat peserta didik untuk menekuni bahwa bisnis dibidang seni ini merupakan salah satu alternatif yang dapat mendatangkan sumber penghasilan tambahan.

Beberapa permasalahan yang terjadi adalah antara lain: (1) Pelatihan Seni derkorasi atau Seni Merangkai Bunga sebagai media yang dipilih dalam mengkreasikan karya yang bermutu, karena media ini mudah diperoleh di wilayah ini dan bila didukung dengan konsep desain yang baru dan menarik dapat menjadi karya seni yang menjadi pilihan di tengah persaingan dan perkembangan seni terapan. (2) Pelatihan Seni Dekorasi atau Seni Merangkai Bunga merupakan salah satu pilihan bagi peserta didik yang kurang mampu untuk mengembangkan minat wirausaha dibidang seni. (3) Pelatihan Seni Dekorasi atau Seni Merangkai Bunga merupakan salah satu pilihan bagi peserta didik untuk pengembangan dan memacu daya kreativitas di bidang seni rupa.

\section{a. Tujuan Kegiatan}

Tujuan yang akan dicapai melalui kegiatan Pelatihan seni Dekorasi atau Seni Merangkai Bunga ini adalah untuk memberikan bekal pengetahuan dan ketrampilan, kecakapan dan daya kreatif bagi para peserta didik di Seminari Agustinianum Tomohon.

\section{b. Manfaat Kegiatan}

(1) Membuka cakrawala baru dalam mengatasi permasalahan yang berhubungan dengan daya kreativitas dan produktivitas di bidang Seni Rupa.

(2) Memacu daya kreativitas generasi muda selaku generasi yang bertanggung jawab dalam memajukan program pemerintah bagi masyarakat.

(3) Menambah pengetahuan dalam mendidik di bidang seni dan ketrampilan kearah pola praktis, terencana, dan mudah dipahami agar dapat merangsang daya kreasi peserta didik untuk menciptakan kreasi-kreasi baru.

\section{c. Khalavak Sasaran}

Khalayak sasaran dalam kegiatan ini adalah para peserta didik di Seminari Agustinianum
Tomohon, dengan jumlah peserta sebanyak 15 orang.

\section{d. Keterkaitan}

Kegiatan pelatihan ini bersinerji dengan program Pemerintah khususnya dalam bidang pendidikan, yang mengemukakan bahwa tujuan itu bukan semata-mata untuk mencapai pengetahuan praktis yang berguna, melainkan mengutamakan pembentukan moral, kecerdasan dan perasaan artistik setinggi mungkin. Pembentukan tersebut penting dalam kehidupan modern yang menghendaki adanya keseimbangan antara pikiran dan perasaan serta membantu program pemerintah dalam mewujudkan "pengembangan SDM Indonesia seutuhnya”.

\section{e. Kerangka Pemecahan Masalah}

Beberapa permasalahan yang terjadi telah diuraikan diatas, maka kerangka pemecahan masalahnya adalah antara lain: (1) Pelatihan Dekorasi atau Seni Merangkai Janur dan Woka sebagai media yang dipilih dalam mengkreasikan karya yang bermutu, karena media ini mudah diperoleh di wilayah ini dan bila didukung dengan konsep desain yang menarik dapat menjadi karya seni yang menjadi pilihan di tengah persaingan dan perkembangan seni terapan. (2) Pelatihan Dekorasi merupakan salah satu pilihan bagi peserta yang berminat untuk mengembangkan minat wirausaha dibidang seni. (3) Pelatihan Dekorasi merupakan salah satu pilihan bagi peserta didik untuk pengembangan dan memacu daya kreativitas di bidang seni rupa.

\section{KAJIAN TEORITIK}

Prinsip desain adalah suatu cara untuk merancang penyusunan unsur-unsur desain, sehingga tercapai perpaduan yang memberi efek indah dan menarik. Suatu rangkaian bunga akan terlihat indah apabila rangkaian bunga tersebut menerapkan prinsip dan unsur desain. Yang termasuk prinsip desain ialah komposisi (composition), proporsi (proportion), keseimbangan (balance), irama (rhythm), dominan dan aksen (dominance and accent), kesatuan (unity), dan harmoni (harmony).

1. Komposisi (Composition)

Komposisi adalah perpaduan yang harmonis antara unsur atau elemen desain yang digunakan di dalam suatu rangkaian bunga. 


\section{Poporsi (Proportion)}

Proporsi berarti perbandingan. Jadi, keindahan suatu rangkaian bunga dipengaruhi oleh keserasian perbandingan ukuran panjang pendek, besar kecil, maupun jumlah warna materi floral yang digunakan. Untuk memperoleh proporsi yang baik dalam merangkai bunga, ada beberapa hal yang harus diperhatikan, di

antaranya sebagai berikut:

- Perbandingan antara besar wadah dan besar rangkaian bunga.

- Perbandingan antara besar wadah dengan materi floral yang dipilih.

- Perbandingan ukuran antara tinggi rangkaian bunga dan lebar rangkaian bunga (dengan memperhatikan pedoman pada setiap bentuk rangkaian bunga).

- Sebaiknya besar kecilnya rangkaian bunga disesuaikan dengan besar kecilnya tempat atau ruangan tempat rangkaian bunga akan diletakkan.

- Pada waktu merangkai bunga sebaiknya bunga yang kecil dan yang kuncup terletak di bagian atas rangkaian bunga,

- pada waktu merangkai bunga sebaiknya bunga yang berwarna muda terletak di bagian atas, sedangkan bunga yang berwarna tua terletak di bagian tengah atau di bawah rangkaian bunga.

3. Keseimbangan (Balance)

Keseimbangan berarti kestabilan.

Keseimbangan sangat berpengaruh pada hasil akhir rangkaian bunga. Rangkaian bunga yang seimbang secara fisik akan terlihat stabil dan indah. Kita mengenal ada keseimbangan simetris dan keseimbangan asimetris,

Suatu rangkaian bunga dikatakan keseimbangannya simetris apabila rangkaian bagian sebelah kiri terlihat secara visual sama kuat dengan rangkaian di bagian sebelah kanan. Hal ini berarti jumlah, ukuran, bentuk, tekstur dan warna materi floral di rangkaian sebelah kiri sama dengan yang ada di rangkaian sebelah kanan.

Sebaliknya, suatu rangkaian bunga dikatakan keseimbangannya asimetris apabila rangkaian bagian sebelah kiri berbeda atau tidak sama dengan rangkaian bagian sebelah kanan, tetapi secara visual terlihat stabil. Keseimbangan di dalam rangkaian bunga dapat diperoleh dengan memperhatikan penggunaan unsur atau elemen desain seperti garis, bentuk, ukuran, ruang, tekstur, dan warna dari materi floral.

4. Irama (Rhythm)

Pada waktu merangkai bunga, irama dapat diciptakan dengan cara-cara berikut

ini:

- Mengadakan pengulangan (repetition), yaitu menggunakan materi floral yang sama di beberapa tempat yang berbeda.

- Memperhatikan kedalaman (depth). Pada waktu meletakkan materi floral, perhatikanlah posisi materi floral, seperti tinggi, rendah, depan, belakang, atau bagian dalamnya.

- Mengadakan transisi (transtition). Gunakan bunga dari bentuk yang besar, sedang, dan kecil. Sebaliknya, transisi dapat pula dilakukan dengan cara menggunakan warna materi floral yang berbeda dari yang berwarna tua sampai yang berwarna muda atau sebaliknya.

Irama ada yang monoton/statis dan dinamis. Irama monoton atau statis terjadi apabila pada rangkaian bunga tersebut tidak ada pengulangan, kedalaman, dan transisi. Apabila dilakukan pengulangan, kedalaman, dan transisi terjadilah irama rangaian bunga yang dinamis, sehingga menghasilkan rangkaian bunga yang indah dan menarik.

5. Dominan dan aksen (Dominance and Accent)

Suatu rangkaian menjadi indah jika prinsip dominan diterapkan di dalamnya,

yaitu ada bagian/unsur dalam rangkaian yang lebih ditonjolkan daripada yang lain. Contoh penerapan prinsip dominan, yaitu penonjolan warna atau materi floral, misalnya bunga yang tercantik atau unik dalam rangkaian itu. Aksen adalah suatu materi floral/nonfloral yang dipakai dalam rangkaian bunga untuk menarik perhatian. Yang dapat dijadikan aksen, misalnya materi floral/nonfloral yang kecil tapi yang unik atau yang berwarna kontras atau yang dapat menjadi pemanis suatu rangkaian. Sementara itu, ada yang di sebut focal poin, yaitu suatu area dalam rangkaian yang sangat menarik perhatian.

Focal poin itu bisa berbentuk bunga yang besar dan berwarna kontras. Bisa juga focal poin itu berupa lilin, boneka, atau pita yang 
peletakannya bisa di tengah, di atas atau di samping rangkaian bergantung kebutuhannya.

6. Kesatuan (Unity)

Rangkaian yang baik biasanya di dalamnya terdapat kesatuan antara unsur atau elemen yang digunakan di dalam rangkaian tersebut. Kesatuan pada rangkaian bunga dapat diciptakan dengan cara-cara berikut ini:

- Memilih warna materi floral yang sesuai dengan warna wadahnya.

- Mempergunakan warna materi floral yang sama pada beberapa tempat pada rangkaian tersebut meskipun jenis materi floralnya berbeda.

- Mengadakan pengulangan penggunaan materi floral di beberapa tempat dalam rangkaian tersebut.

7. Harmoni (Harmony)

Dalam seni merangkai bunga dan desain floral yang diartikan dengan harmoni ialah ketepatan atau keselarasan penggunaan unsur dan elemen desain pada rangkaian bunga sehingga dihasilkan rangkaian bunga yang serasi, indah dan menarik.

Keharmonisan dalam rangkaian bunga dapat diciptakan dengan jalan, antara lain

- memperhatikan kombinasi warna, bentuk, maupun tekstur pada rangkaian bunga;

- memperhatikan keserasian antara penggunaan wadah dengan keseluruhan rangkaian bunga, dan

- memperhatikan jarak antara masing-masing materi floral.

\section{Unsur Desain}

Unsur desain dikenal juga dengan istilah elemen desain. Elemen desain ialah visualisasi dari materi floral yang dipakai dalam rangkaian bunga. Yang termasuk unsur atau elemen desain ialah garis (line), bentuk (form), ruang (space), tekstur (texture), dan warna (color).

1. Garis (line)

Dalam seni merangkai bunga dan desain floral, unsur garis terlihat jelas secara kasat mata. Kita mengenal adanya garis lurus, garis melengkung, dan kombinasi garis lurus dan garis melengkung. Apabila kita perhatikan berbagai macam materi floral, terlihat adanya materi floral yang bergaris lurus seperti sedap malam, gladiol, dan liatris. Di samping itu, ada pula materi floral yang bergaris melengkung seperti calla lily dan tulip.

Apabila dilihat darisifatnya, garis lurus bersifat statis, sedangkan garis melengkung bersifat dinamis. Rangkaian bunga yang banyak mengggunakan materi floral yang bergaris lurus, akan memberi kesan tegas, kaku, dan stabil. Sebaliknya, rangkaian bunga yang banyak mempergunakan materi floral yang bergaris melengkung akan terlihat luwes. 2. Bentuk (Form)

Dalam seni merangkai bunga dan desain floral, unsur bentuk terlihat dari bentuk rangkaian bunganya. Secara keseluruhan rangkaian bunga harus terlihat bentuknya. Bentuk geometris terlihat pada rangkaian bunga gaya Eropa, seperti rangkaian bunga bentuk dasar bulat, oval horisontal, segitiga simetris sama sisi, segitiga asimetris, segitiga sama kaki, segitiga siku, L, T terbalik, kipas, segi empat, vertikal, diagonal, hogarth, bulan sabit (crescent), dan lengkung terbalik.

Kita mengenal adanya bentuk tertutup (close form) dan bentuk terbuka (open form).

Yang dimaksud dengan bentuk tertutupialah apabila rangkaian bunga tersebut mengggunakan banyak materi floral yang dirangkai secara padat atau terisi

penuh, misalnya rangkaian bunga bentuk bulat, horisontal, segitiga, segi empat dan kipas. Yang dimaksud dengan bentuk terbuka ialah apabila rangkaian bunga tersebut menggunakan materi floral yang dirangkai tidak padat atau tidak penuh, tetapi jaraknya berjauhan, misalnya rangkaian bunga bentuk vertikal ,T terbalik, hogarth, crescent, lengkung terbalik , "L", rangkaian bunga modern, dan rangkaian Ikebana.

3. Ruang (Space)

Dalam suatu rangkaian bunga tiga dimensi, kita melihat adanya jarak antara satu materi floral dengan materi floral yang lain. Jarak inilah yang disebut dengan ruang (space). Kita mengenal adanya ruang positif dan ruang negatif. Suatu rangkaian bunga yang terdiri atas materi floral yang dirangkai secara padat atau terisi penuh berarti berbentuk tertutup, mempunyai ruang positif. Rangkaian bunga yang terdiri atas materi floral yang dirangkai tidak padat, mempunyai jarak yang berjauhan antara satu materi floral dengan materi floral yang lain, berarti berbentuk terbuka. Jarak dikatakan negatif jika di dalam rangkaian 
tersebut ada ruangan kosong antara materi floral.

4. Tekstur (Texture)

Apabila kita perhatikan dengan kasat mata atau dengan cara diraba, ada materi floral, yaitu bunga atau daun yang permukaannya kasar, halus, kusam, atau berkilau. Sifat permukaan bunga atau daun inilah yang dinamakan tekstur.

5. Warna (Colour)

Dalam seni merangkai bunga dan desain floral, teori warna sangat penting dipelajari karena warna merupakan salah satu unsur atau elemen desain rangkaian bunga yang paling menjadi perhatian. Warna dasar disebut hue, sedangkan nilai warna disebut pula value, kadar warna disebut chroma.

\section{HASIL DAN PEMBAHASAN}

Sebelum merangkai bunga, yang harus diperhatikan terlebih dahulu adalah tujuan merangkai bunga tersebut; apakah untuk seharihari di rumah atau apakah untuk keperluan pesta. Rangkaian bunga untuk pesta pun bermacam-macam, misalnya pesta ulang tahun, perkawinan, hari raya Natak, Tahun Baru, Valentine, dan lain-lain. Di samping itu, kita juga harus mengetahui atau membayangkan akan diletakkan di mana rangkaian bunga tersebut. Berdasarkan tujuan dan tempat peletakkan rangkaian bunga, kita menentukan bentuk rangkaian bunga yang akan dibuat, wadah yang akan dipakai, materi floral, aksesoris, peralatan, dan mekanik yang diperlukan.

Seorang perangkai bunga akan dapat bekerja dengan teratur dan tenang apabila disediakan ruangan atau tempat untuk merangkai dengan penerangan yang cukup terang, ada ventilasi dan selalu dijaga kebersihannya. Di dalam ruangan tersebut tersedia meja kerja yang mudah dibersihkan dan tahan air. Meja kerja tersebut

harus dialasi dengan plastik agar tidak basah. Untuk merangkai bunga diperlukan sarana penunjang berupa peralatan dan mekanik.

\section{Peralatan}

Peralatan di sini adalah segala sesuatu yang digunakan untuk merangkai bunga dan yang tetap dimiliki si perangkai bunga; tidak terbawa dengan rangkaian bunganya apabila rangkaian tersebut dijual atau diberikan kepada orang lain.
Yang termasuk peralatan adalah sebagai berikut:

1. Alat potong. Alat potong yang digunakan untuk merangkai bunga, antara lain

- gunting bunga yang khusus untuk bunga dan daun

- gunting kertas yang berguna untuk menggunting kertas

- gunting kain/pita

- pisau /cutter untuk memotong bantalan bunga (floral foam)

- tang potong (cutting plier) untuk memotong kawat atau mengencangkan ikatan.

Perlu diperhatikanpula bahwa keadaan alat potong untuk merangkai bunga harus bersih dan tajam.

2. Tempat air untuk merangkai bunga dapat berupa

- wadah yang tidak bocor, misalnya e mber plastik untuk menyimpan materi floral.

- Wadah yang tidak bocor dengan permukaan lebar yang berguna untukmerendam bantalan bunga.

3. Semprotan untuk menyemprot materi floral yang sudah dirangkai agar tetap segar.

4. Tempat sampah atau kantong sampah plastik sebagai tempat untuk membuang sampah pada waktu merangkai bunga.

5. Serbet yang berguna untuk membersihkan meja agar tidak ada air yang tergenang di meja kerja, sehingga keadaan meja kerja tetap bersih. Di samping itu, serbet berguna pula untuk membersihkan serta mengeringkan wadah atau peralatan lain yang akan digunakan.

6. Celemek yang berguna untuk melindungi pakaian si perangkai pada waktu merangkai bunga.

\section{Mekanik}

Mekanik ialah segala sesuatu yang digunakan pada waktu merangkai bunga yang kemudian terbawa dengan rangkaian bunganya apabila rangkaian tersebut dijual atau diberikan kepada orang lain. Yang termasuk mekanik adalah sebagai berikut :

1. Wadah

Wadah adalah tempat untuk merangkai bunga. Kata lain untuk wadah ialah jambangan bunga atau vas. Ada wadah yang 
terbuat dari keramik, plastik, fiberglass, kaca atau gelas, asongan, kayu, dan rotan. Salah satu syarat yang harus dipenuhi dalam memilih wadah adalah kokoh dan stabil.

Ditinjau dari permukaan wadah atau mulut wadah, ada wadah yang permukaannya berbentuk bulat, oval atau lonjong, bujur sangkar, dan persegi panjang. Dilihat dari ukurannya, ada wadah yang dikategorikan sebagai wadah rendah, sedang, tinggi, dan bebas.

- Wadah rendah adalah wadah yang lebar permukaan wadahnya lebih besar dari tinggi wadah tersebut.

- Wadah sedang adalah wadah yang permukaannya sama atau hampir sama dengan tinggi wadah.

- Wadah tinggi adalah wadah yang lebar permukaannya lebih kecil daripada tinggi wadah tersebut.

Untuk perangkai bunga pemula ukuran wadah ditentukan sebagai berikut:

- Wadah rendah adalah wadah dengan ketinggian berkisar antara 0--15 cm

- wadah sedang adalah wadah dengan ketinggian berkisar antara $16--25 \mathrm{~cm}$

- wadah tinggi adalah wadah dengan ketinggian berkisar antara 26 sampai dengan $50 \mathrm{~cm}$

Ditinjau dari warnanya, warna wadah yang paling umum dipakai adalah wadah dengan warna putih, abu abu, dan hitam. Di samping itu ada wadah yang berwarna hijau, coklat, atau merah. Warna wadah tidak terbatas, tetapi dalam membuat rangkaian warna wadah harus disesuaikan dengan rangkaian bunga secara keseluruhan.

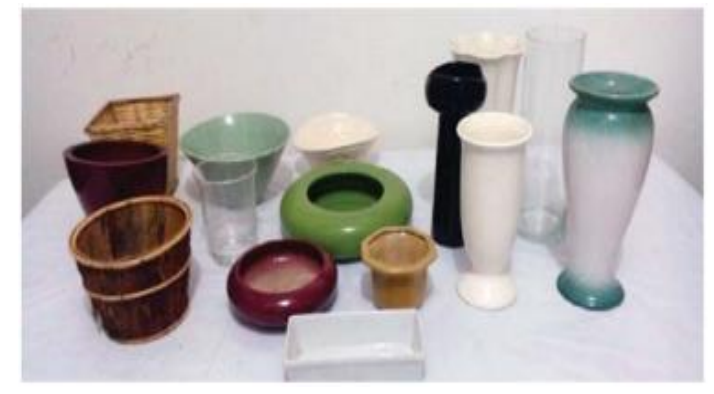

Jenis-jenis wadah

Sumber : Repro Ajeng Prasasti, Buku Teknik Merangkai Bunga untuk Pemula, Halaman 21.

\section{Bantalan Bunga (Floral Foam)}

Di pasaran, kita mengenal bantalan bunga (floral foam) basah dan kering. Bantalan bunga basah digunakan untuk merangkai bunga segar. Bantalan bunga segar biasanya berwarna hijau tua, permukaannya halus dan dapat menyerap air, sehingga materi floral yang ditancapkan dapat bertahan beberapa hari dalam keadaan segar. Saat ini sudah banyak dijual bantalan bunga basah yang berwarna-warni. Bantalan bunga sebaiknya disimpan dalam keadaan kering. Bantalan bunga kering berwarna hijau muda, bertekstur kasar dan tidak dapat menyerap air. Bantalan ini digunakan untuk merangkai bunga kering atau bunga artifisial.

Agar bantalan bunga dapat berfungsi dengan baik, yaitu sebagai sarana untuk menyimpan air, Kita harus memperhatikan cara merendam bantalan bunga tersebut. Caranya adalah sebagai berikut:

- tempat air yang permukaannya lebar; dapat berupa wadah yang tidak bocor, misalnya ember atau baskom dari plastik diisi dengan air kurang lebih tiga perempat bagian.

- bantalan bunga diletakkan di atas air dan jangan ditekan.

- biarkan sampai tenggelam sendiri. Jika sudah tenggelam berarti bantalan bunga sudah cukup mengisap air dan sudah siap untuk digunakan.

Perlu diingat bahwa merendam bantalan bunga jangan terlalu lama, karena akan mudah hancur.

Cara mengisi wadah dengan bantalan bunga adalah sebagai berikut :

- Siapkan wadah yang akan digunakan untuk merangkai bunga.

- Jika wadah terbuat dari asongan, rotan atau kayu, wadah harus dialasi dahulu dengan plastik agar air tidak merembes.

- Bantalan bunga diukur sesuai dengan lebar wadah, dengan ketinggian minimum setengah tinggi wadah yang masuk ke dalam wadah.

- Ketinggian wadah di atas bibir wadah berkisar 3--5 cm untuk memudahkan penancapan materi floral.

- Bantalan bunga yang tajam sebaiknya dipotong agar area penancapan materi floral menjadi lebih luas. 
- Wadah yang sudah diisi bantalan bunga siap digunakan untuk merangkai Bunga.

- Pastikan bantalan bunga dalam wadah dalam keadaan stabil, kuat, dan tidak bergerak untuk memudahkan dalam perangkaian bunga.

- Apabila tidak tersedia antalan bunga, dapat juga digunakan mos (daun panjang yang merambat), enceng gondok, atau pelepah daun pisang yang diikat menjadi satu dan dimasukkan ke dalam wadah. Yang harus diperhatikan dalam hal ini adalah irisan pemotongannya menghadap ke atas atau dalam posisi mengikuti tinggi wadah.

\section{Kawat Bunga}

Kawat bunga digunakan sebagai alat untuk menyangga tangkai, daun, dan bunga agar materi floral dapat digunakan sesuai dengan kebutuhkan. Selain itu, kawat bunga dipakai sebagai alat pengikat. Kawat bunga ada yang tebal dan halus.

Ketebalan atau kehalusan kawat bunga dapat ditentukan dari nomornya. Makin besar nomornya, makin halus kawatnya. Kawat yang paling halus adalah kawat dengan nomor 30. Ada kawat yang bernomor 30, 28, 26, 24, 22, 20, 18, dan 16. Kawat lain yang dapat digunakan ialah kawat bangunan, kawat dinamo, kawat tembaga, dan kawat aksesoris.

\section{Alat Bantu Lain}

Alat bantu lain yang sering dipakai dalam merangkai bunga adalah kawat ayam, cellotape, doubletape, floraltape, tusuk sate, tube, tali, pita, dan perekat.

- Kawat ayam digunakan untuk menutup bantalan bunga terutama untuk wadah rangkaian bunga yang besar. penggunaan kawat ayam menjadikan bantalan bunga tidak mudah pecah .

- Cellotape dan doubletape adalah sarana yang digunakan sebagai perekat di dalam perangkaian bunga.

- Floraltape adalah bahan seperti cellotape berwarna hijau atau warna lain yang mengandung perekat dan berguna untuk merapikan rangkaian agar kawat tidak terlihat.

- Tube adalah wadah kecil yang bisa diisi air dan terbuat dari plastik atau kaca. Tube digunakan sebagai wadah materi floral agar bisa menyerap air. Jika materi bunga pendek, materi bunga bisa dipanjangkan dengan memasukkannya ke dalam tube. Selanjutnya, tube disambung dengan tusuk sate atau tangkai sesuai kebutuhan panjang yang diperlukan.

- Tusuk sate digunakan sebagai alat penyambung tangkai materi floral yang pendek. Selain itu, tusuk sate berfungsi untuk memperkuat atau menyangga bantalan bunga yang bertumpuk agar tidak goyang.

- Macam-macam tali, seperti tali rafia, tali rami, atau ta li go ni berguna sebagai alat pengikat di dalam perangkaian bunga.

- Macam-macam perekat seperti power glue atau hot glue, cold glue, Fox, dan UHU. Hot glue berguna untuk merekatkan rantng, kulit kayu, dan kayu.

\section{Jenis- Jenis Materi Floral dan Nomenklaturnya.}

Jika ditinjau dari bentuknya, bunga mempunyai berbagai macam bentuk, seperti bunga berbentuk bulat (focal flower), garis lurus (line flower), garis melengkung, bentuk khusus (form flower), bunga pengisi (filler flower), dan bunga massa.

Contoh bunga yang berbentuk bulat (focal flower), diantaranya sebagai berikut :

- Anyelir : Dianthus caryophillus

- Dahlia : Dahlia

- Mawar : Rosa

- Gerbera : Gerbera jamesonii

- Krisan standar : Chysanthemum

Contoh bunga garis lurus (line flowers), diantaranya sebagai berikut.

- Gladiol : Gladiolus

- Sedap malam: Polianthes tuberrosa

- Liatris : Liatris spicata

- Snapdragon : Anthirhinum majus

- Sorghum : Sorghum halepanse

- Pisang-pisangan :Heliconia

Contoh bunga garis melengkung, di antaranya sebagai berikut:

- Calla lily : Zantedeschia

- Tulip : Tulipa

Contoh bunga berbentuk khusus (form flower), di antaranya sebagai berikut:

- Anthurium 
- Bird of paradise : Strelitzia reginae

- Iris

- Lily : Casablanca, asia ; lilium sp

- Jengger ayam (lancip) : Celosia argentea plumrosa

- Jengger ayam (tebal) : Celosia cristata

- Lengkuas merah:Alpinia purpurata

Contoh bunga pengisi (filler flower) di antaranya sebagai berikut:

- Aster : Aster ericoides

- Bunga kancing : Gomphrena globosa

- Baby's breath : Gypsophila

- Krisan puma, kermit : Crysanthemum spray

- Carnation spray: Anthus

- Caspea : Limonium latifolium

- Margrit / peacock : chinensis

- Rasidah: Solidago canadensis

- Statice : Limonium sinuatum

Contoh bunga massa, di antaranya sebagai berikut :

- Hortensia : Hydrangea marcrophylla

- Soka: Ivora stricia

- Agapanthus.

Contoh daun yang banyak digunakan di dalam rangkaian bunga antara lain adalah sebagai berikut :

- Anjuang/andong : Cordyline terminalis

- Asparagus : Asparagus plumosus

- Asparagus Kristusdoren : Asparagus denslorus "sprengeri"

- Asparagus bintang : Asparagus "myriocladus" atau Asparagus umbellatus

- Buntut bajing : Asparagus densifloru "meyeri"

- Daun kemuning

- Florida beauty

- Futoi : Equisetum

- Kadaka : Asplenium

- Kuping gajah

- Leather leaf : Arachnoides

- Pakis kelabang : Neprolephis exaltata

- Palem : Palmae

- Palem kuning

- Pandanus

- Philodendron

- Pedang-pedangan

- Puring : Codiaeum
- Ruskus

- Sirih gading : Epipremnum

- Sri rejeki

- Stock/tifa

- Daun kelapa/janur

\section{Pengetahuan tentang Janur dan Woka}

Janur adalah daun kelapa yang masih muda berwarna kuning keputihan. Sedangkan Woka adalah sejenis pohon palem perdu yang biasa tumbuh di hutan, ujung Woka yang muda dan masih kuncup biasa digunakan sebagai rangkaian dekorasi,. Warna yang kuning segar sangat menarik bila dibentangkan menyerupai kipas. Janur dan Woka dipilih sebagai bahan rangkaian hiasan dekorasi karena memiliki keunikan, ciri khas dan nilai seni tersendiri. Janur bisa bertahan 1 minggu, sedangkan Woka lebih cepat layu. Kelebihan dari Woka adalah warnanya akan bertahan lebih lama dan cenderung berwarna putih meskipun tidak lagi segar. Sedangkan Janur akan berubah warnanya menjadi coklat bila sudah layu. Janur bila dirangkai harus menggunakan hekter sebagai sarana untuk menyambung helai demi helai daunnya. Sedangkan Woka sdh berbentuk rangkaian yang menyatu, tinggal diiris sesuai dengan desain atau rancangan yang dikehendaki.

Daun woka teksturnya lebih lembut bila dibandingkan dengan Janur. Cara mengirisnyapun lebih mudah dan cepat karena daunnya tipis dan lembut. Janur dan Woka dapat dibentuk menjadi aneka rangkaian dan ragam hiasan yang dapat membuat suasana menjadi indah, segar, semarak alamiah.

Ragam hiasan Janur dan Woka dibagi menjadi dua golongan, yaitu rangkaian hiasan berbentuk tunggal dan majemuk. Hiasan Janur dan Woka bentu tunggal adalah rangkaian hiasan yang terdiri dari satu bentuk. Contohnya bentuk keris, udang, ketupat, belalang, burung, jagung, cakra, dan bintang. Rangkaian Hiasan berbentuk majemuk adalah gabungan dari beberapa hiasan Janur dan Woka bentuk tunggal sehingga membentuk rangkaian tertentu. Contohnya hiasan duduk, hiasan dinding, hiasan gantung pohon Janur, umbul-umbul, dan kembar mayang.

Kembar mayang diartikan sebagai dua bentuk yang sama. Pada umumnya kembar mayang dipakai pada acara pernikahan dan ditempatkan 
di sebelah kanan dan kiri pelaminan. Selain kembar mayang, ada hiasan duduk dengan gaya bebas. Hiasan ini biasanya selain bahan baku Janur dan Woka, digabung dengan bunga segar ataupun buah-buahan. Rangkaian hiasan gaya bebas biasanya dipakai sebagai pendamping kembar mayang atau diletakkan disamping kiri dan kanan pintu masuk gedung tempat acara dilaksanakan.

\section{Bentuk Desain Rangkaian Bunga}

Oval (Lonjong)

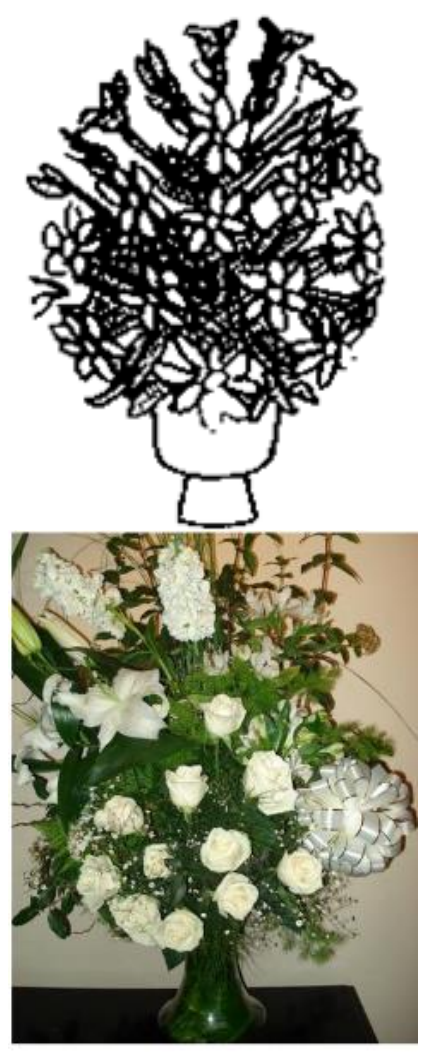

1. Kipas (Fan)

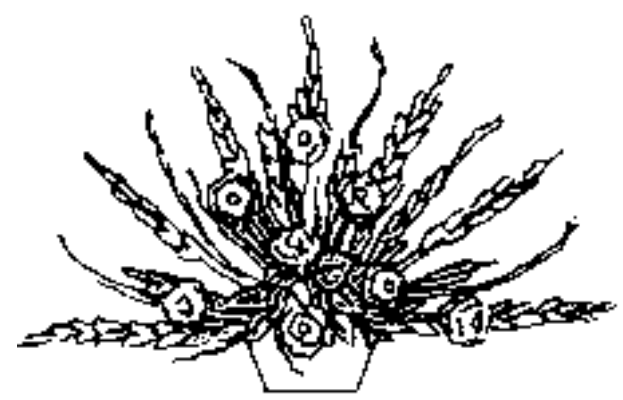

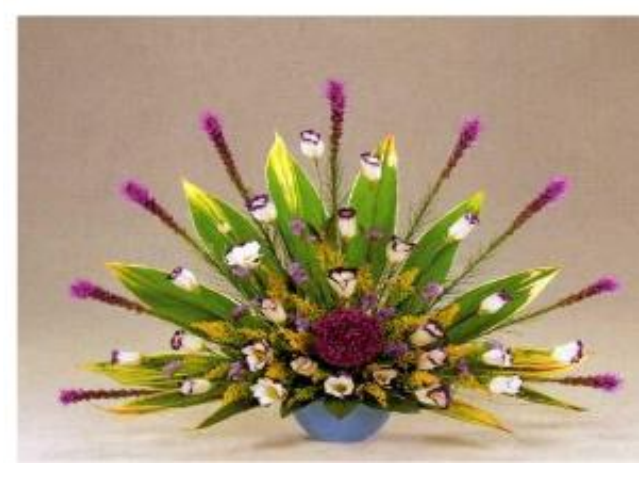

2. Triangle (Segitiga)
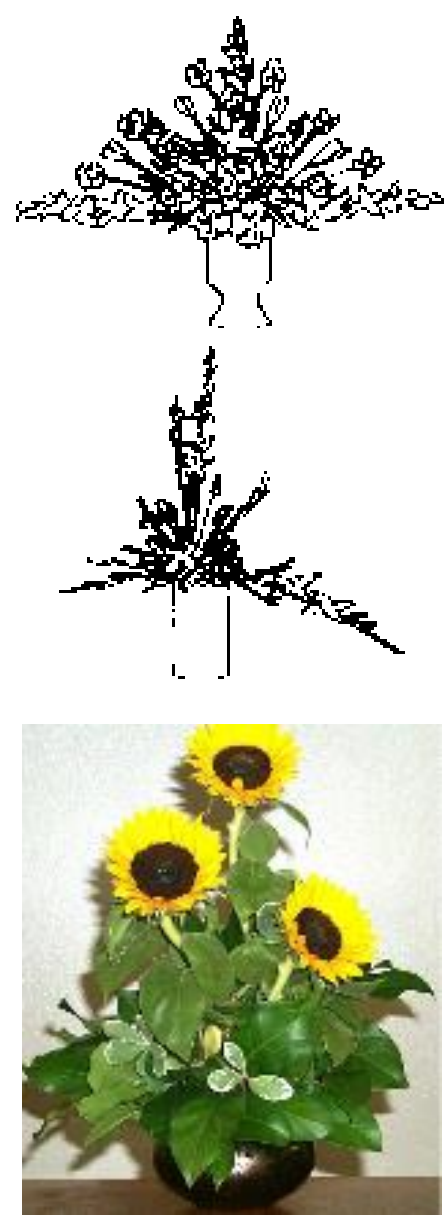

3. Right Angle (Desain membentuk huruf L) 

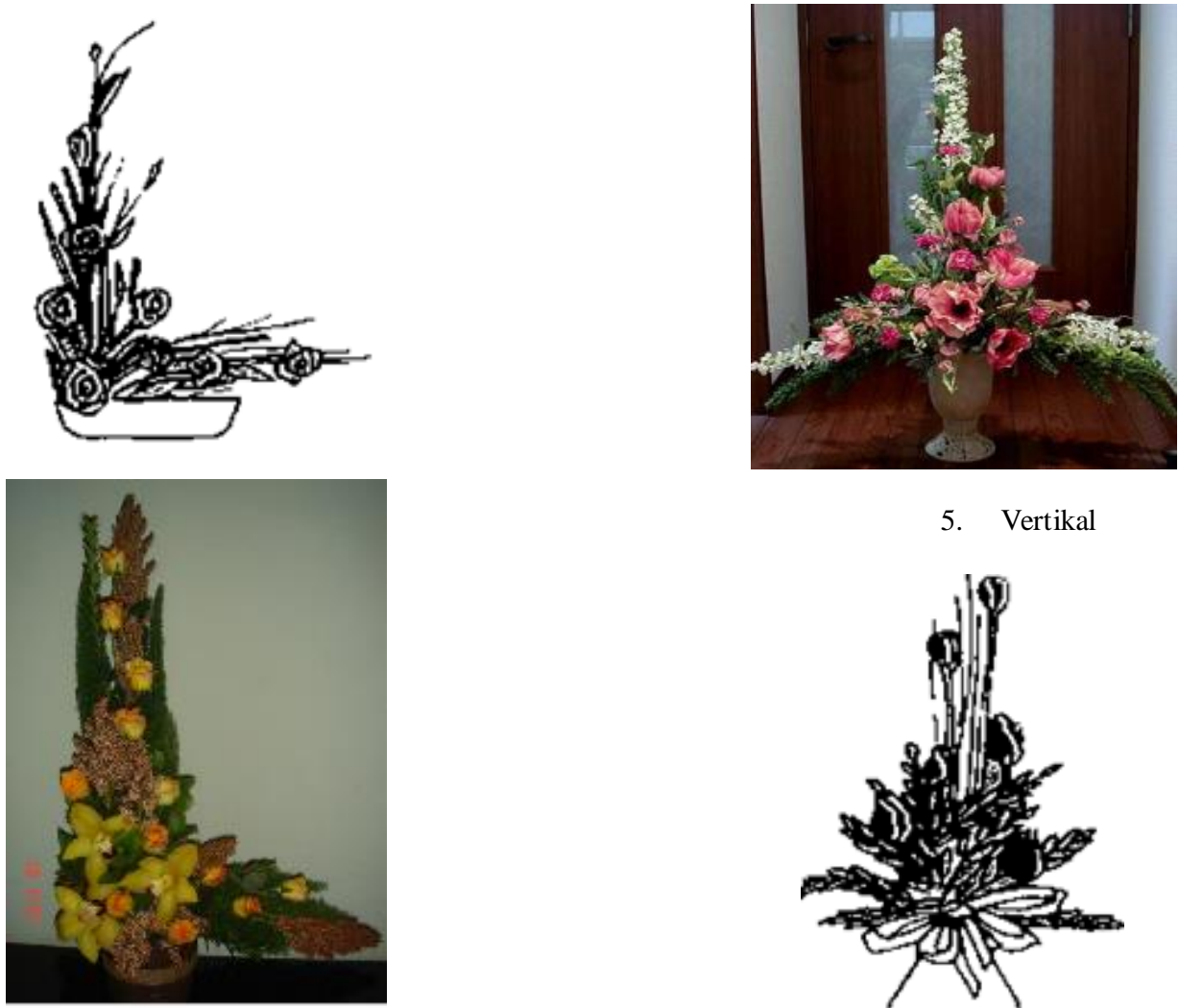

5. Vertikal
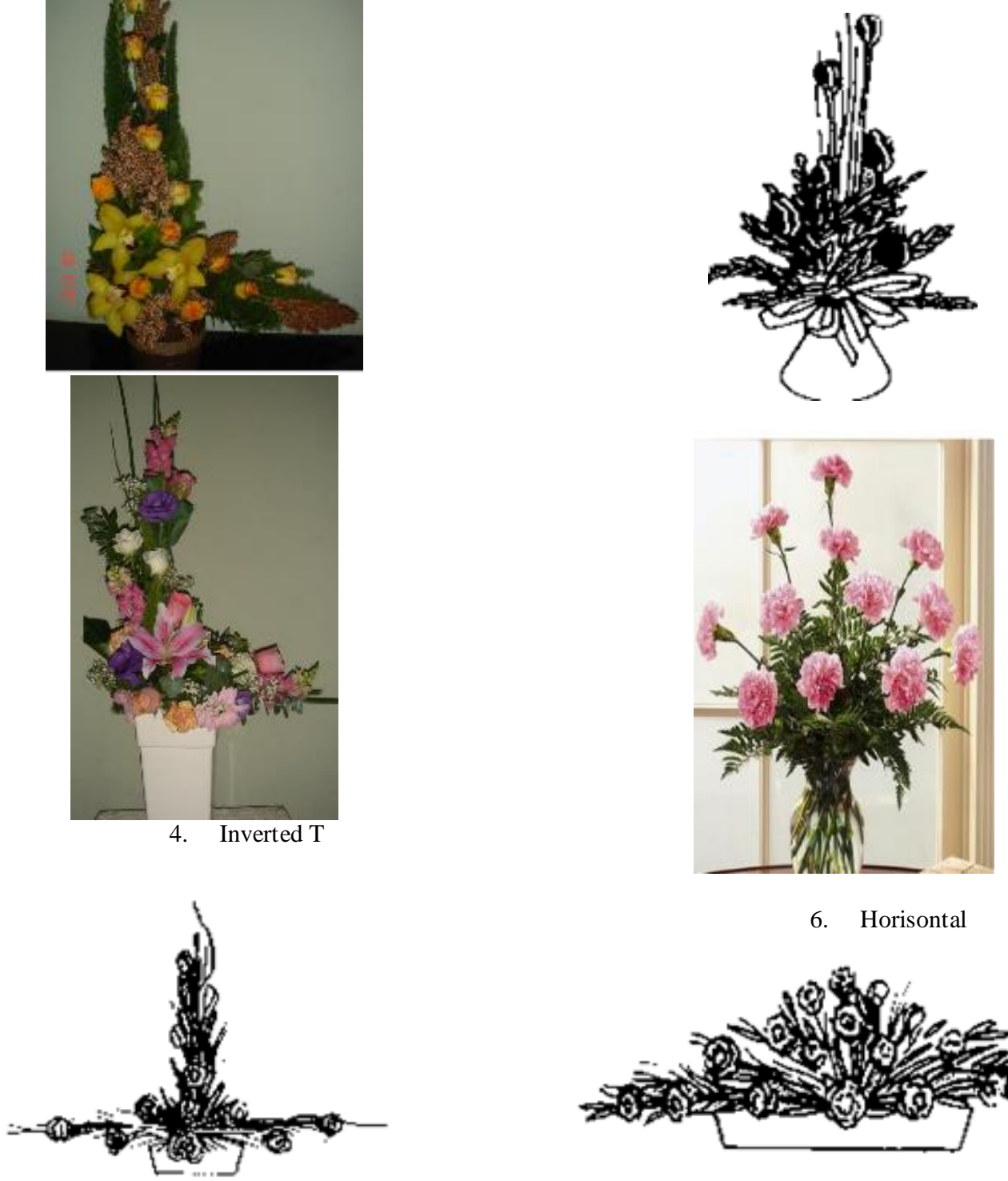

6. Horisontal

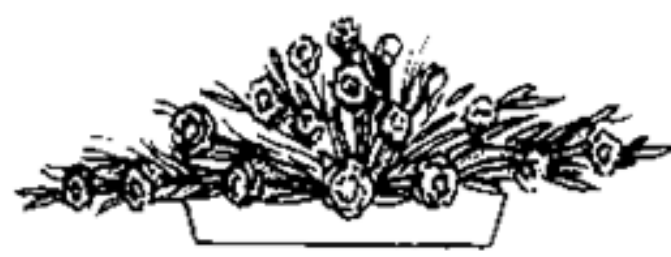




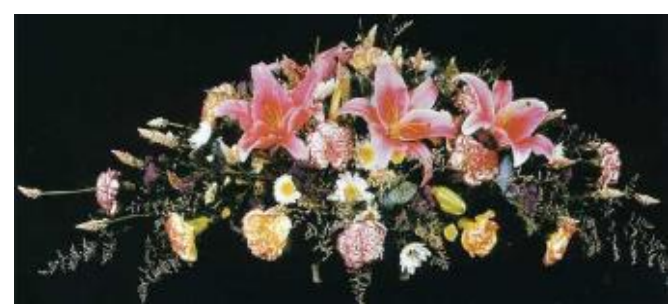

7. Diagonal
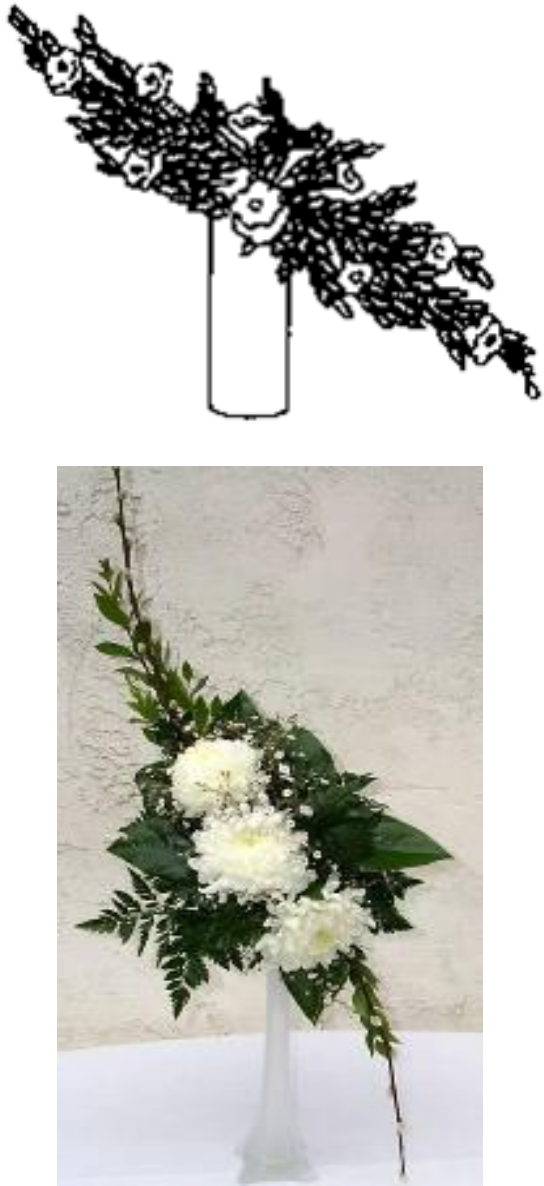

8. Cresent (Bulan sabit)

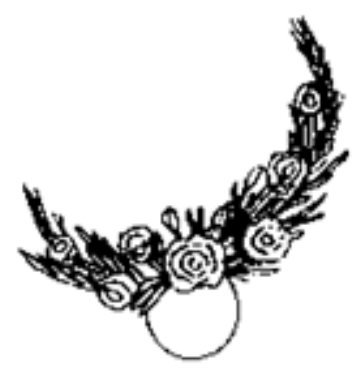

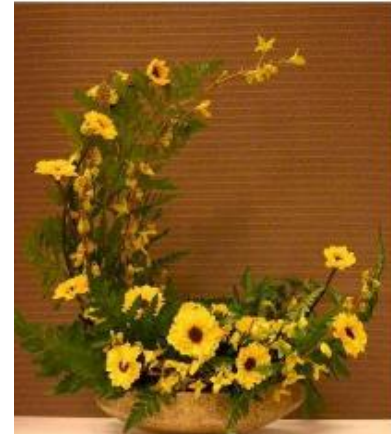

9. Hogarth Curve (Rangkaian berbentuk S)
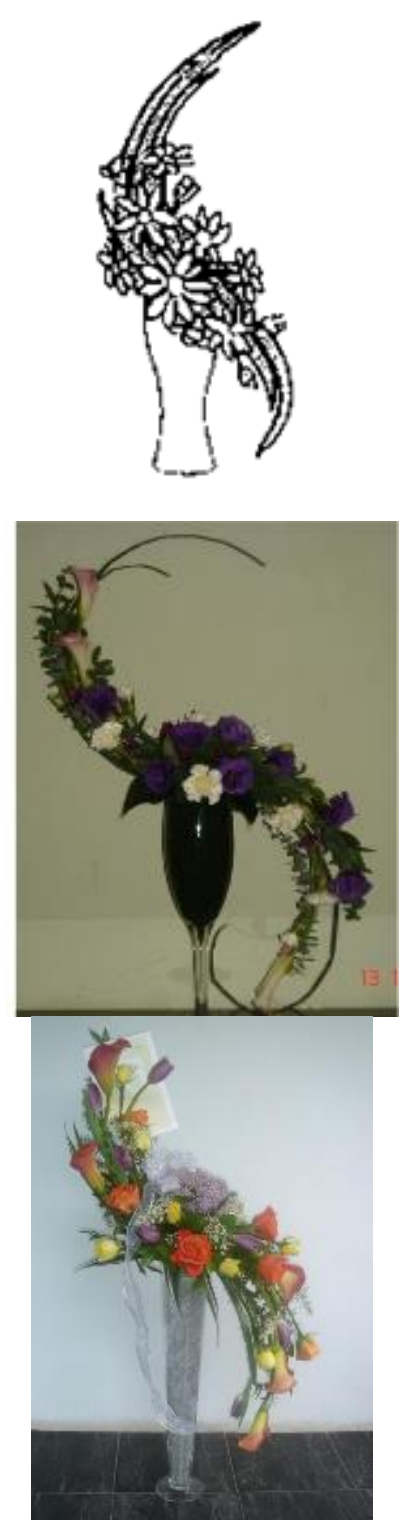


\section{KESIMPULAN}

Produk dari hasil Dekorasi atau Merangkai bunga, dapat dipasarkan dengan jalan menerima pesanan dari keluarga, teman, atau tetangga. Jangan merasa puas dengan hasil yang dibuat, tetapi teruslah berlatih dan berkreasi, sehingga hasilnya tidak monoton dan membosankan.

Merangkai bunga adalah suatu seni. Jadi, kita harus terus menambah pengetahuan dan keterampilan dengan terus mencoba, melihat kreasi perangkai bunga melalui pameran, di toko-toko bunga, demonstrasi, majalah, internet, atau media yang lain. Usaha merangkai bunga ini memerlukan kesabaran, ketekunan, ketelitian, dan keberanian. Jangan cepat putus asa; tingkatkan daya kreasi serta perhatikan selera konsumen dan tren yang sedang berlaku atau yang disenangi pada saat itu. Perlu diingat pula jika sudah mulai merambah dunia bisnis, jangan lupa untuk membuat buku kas sederhana. Catatlah setiap pengeluaran maupun pemasukan meskipun jumlahnya sedikit. Pada mulanya usaha ini dapat dilakukan untuk keperluan sendiri. Lama-lama, jika tekun, kita dapat mengembangkannya menjadi usaha rumah tangga yang dapat menjadi penghasilan keluarga.

Sebagai perangkai bunga pemula, terlebih dahulu kita harus menguasai pembuatan rangkaian bunga pola dasar bentuk bulat, segitiga, dan vertikal. Hal itu karena ketiga bentuk tersebut yang termudah,

tetapi tetap disenangi oleh konsumen. Namun, perangkai harus benar-benar memahami dan menekuni rangkaian tersebut, sehingga dapat dijadikan dasar untuk merangkai bentuk rangkaian yang lain. Sebelum merangkai bunga ketiga bentuk ini, persiapkanlah sarana penunjang yang meliputi peralatan dan mekanik. Pilihlah wadah yang sesuai dengan bentuk rangkaian bunga yang akan dirangkai. Perhatikan cara merendam bantalan bunga dan cara mengisi bantalan bunga ke dalam wadah Pemasangan bantalan bunga harus stabil, kokoh, dan

tidak bergoyang agar memudahkan penancapan tangkai bunga dan hasil rangkaian bunga kokoh dan seimbang.

Rangkailah ketiga pola dasar tersebut dengan memperhatikan urutan-urutan pekerjaan. Perhatikan sketsa dari penancapan tangkai bunga untuk menghasilkan bentuk rangkaian yang baik. Untuk merangkai rangkaian bunga bentuk bulat, pilihlah bunga yang berbentuk bulat sebagai bunga utama, ditambah dengan bunga yang berbentuk bulat pula, tetapi dengan ukuran atau warna yang berbeda.

Sebagai pemanis tambahkan bunga pengisi dan daun yang yang teksturnya sama.

Untuk rangkaian bunga bentuk segitiga dan vertikal, pilihlah bunga yang berbentuk garis lurus untuk membentuk garis segitiga dan vertikal. Kemudian, tambahkan bunga berbentuk bulat, bunga pengisi, dan daun. Berdasarkan teori warna yang sudah dipelajari, pilihlah paduan warna atau kombinasi warna monokromatik, analog, atau komplementer. Kuasai setiap pengertian prinsip dan unsur desain.

Terapkan ketujuh prinsip desain dan unsur desain yang sudah dikuasai dalam merangkai bunga,

Sehingga terlihat adanya kesatuan dan keharmonisan yang menghasilkan rangkaian indah dan menarik dan bernilai jual baik. Jangan lupa untuk mempelajari dengan cermat cara menghitung harga jual, sehingga keterampilan yang diperoleh dapat menambah penghasilan sendiri dan keluarga.

\section{REFERENSI}

Mahyudin, As Aulina. 2000. Seni Tata Rangkai

Bunga. Jakarta: Gramedia Pustaka Utama.

Wahyudi, Lusy. 2008. Panduan Merangkai bunga:

A guide to Flower Arranging. Jakarta: Gramedia Pustaka Utama,.

Wiharsa, Herliana. 2008. Merangkai Bunga Hasil

Kebun Sendiri. Jakarta: Prima Infosarana Media. 